\title{
The impact of interdisciplinary dynamic images on public perception
}

\author{
ChaoYuan $\mathrm{Shi}^{1, \mathrm{a}}$, $\mathrm{Li} \mathrm{Gu}^{* 1, \mathrm{~b}}$ \\ ${ }^{1}$ Nanjing Technology University Nanjing, China
}

\begin{abstract}
Dynamic image, usually defined as motion graphics or dynamic graphics, is a kind of image art based on art design and computer science. In a broad sense, dynamic image is a discipline that integrates animation, film, and graphic design. Its expression content is more refined and straightforward than animated movies. It is more comprehensive than graphic design in conveying information. There are more types of dynamic images in the new media era. There are virtual reality technologies that rely on computer science and interactivity, and there are self-media on the Internet. Together with traditional media, they have more and more impact on the public's cognition. The interdisciplinary dynamic image is a visual language based on the dynamic image and interdisciplinary boundaries. It is main feature is to use dynamic images to express the main content of something, event or thought, a moving image made for the purpose of improving the public's understanding of the corresponding thing, In the interdisciplinary dynamic images, the concreteness and narrative nature of the dynamic images are weakened, and the non-representation and scientific are more emphasized.
\end{abstract}

\section{The main development form of dynamic images}

Image is the most important component of dynamic image, mainly including vector graphics, pixel graphics, real shot or produced images, etc. In a non-dynamic state, it can convey the author's intentions and information to a certain extent. Images can be divided into static images and dynamic images according to the length of time. Static images only show one moment of a certain thing, usually using traditional paper as the carrier ${ }^{[1]}$. The dynamic image is to record the time period of things, and record the development of things in multiple frames according to the linear development of time. Screens based on lightemitting diodes are usually used as carriers.

The history of moving images can be traced back to Joseph Plateau (October 14, 1801-September 15, 1883), Plateau was a famous Belgian physicist in the 19th century. Prato discovered the persistence of vision of fast-moving objects by looking directly at the sun, which became the theoretical basis for subsequent animation and film works. Prato published On the Properties of Light Produced in the Visual Organs and invented the Phenakistoscope. Phenakistoscope divides a disc evenly into 16 sectors and draw dance moves on another disk. When the two disks move quickly, the images seem to merge together, creating the visual illusion of dancers moving. In contemporary design, dynamic images often exist in the lives of the public relying on screens. Saul Bass is often considered the originator of motion picture design, the title of his masterpiece Vertigo is a milestone in film history. The posters of Vertigo complement the entire movie, giving full play to the power of dynamic graphics. In the 20th century, the invention of television enabled digital dynamic images to be widely disseminated and preserved among the masses. The invention of the smartphone at the beginning of the 21 st century made the public become accustomed to obtaining information anytime and anywhere.

With the development of dynamic images and information technology. The current dynamic image has got rid of the limitation of two-dimensional screen from a three-dimensional perspective brings people a more realistic and shocking experience. Virtual reality technology is based on computer science and combine artificial intelligence, kinematics and use certain interactions. A virtual environment with touch, hearing, vision, etc. So that users can get a realistic immersive experience in the virtual world.

\section{The impact of interdisciplinary dynamic images on public perception}

In the past, the way for the public to gain cognition was limited to paper, two-dimensional, flat books or their own practice. In the era of new media, dynamic images integrate a large amount of three-dimensional, dynamic, and audio-video combined information to spread to every corner of the world at the speed of light. The ways for the public to gain cognition have also been expanded. Through the dissemination of dynamic images, the public's awareness of art, science, and worldview values has been improved.

ae-mail:911259236@qq.com

b*e-mail: 1023602419@qq.com 


\subsection{Raise the public's awareness of humanistic aesthetics}

Traditional museums generally adopt the form of text introduction and tour guide but the content contained in this form is too single, and tourists cannot obtain a complete understanding of the corresponding cultural relics, and the content is dull and boring, so tourists rarely stop to watch. With the rapid development of dynamic images, the museum has gradually abandoned the guided tour mode, but has changed to tourists as the main body, introducing the museum's cultural relics to tourists in the form of documentaries through dynamic images. Museums often place a large screen in the lobby to display the introduction of the museum, and each cultural relic is equipped with a corresponding documentary. This not only improves the interest of the video, but also improves visitors' awareness of the historical background and cultural connotation of the collection. ${ }^{[2]}$

Traditional art galleries are not very attractive to the public with less exposure to art, because the main body of art design appreciation needs to have the ability to interpret art design works. If one can not understand the symbols used in art design works, one will cannot understand its meaning and cannot appreciate it. For the same art design work, different viewers have different understandings of the art design language due to their different levels of mastery of the art design language, and thus come to different interpretations. This is the subjectivity, relativity and variability in interpretation. ${ }^{[3]}$

However, modern art galleries apply virtual reality technology and dynamic images to make art galleries get rid of the simple 'seeing' form and enter the 'playing' mode. Van Gogh's "Starry Sky" Pavilion is designed with Van Gogh's works as the theme. The dynamic light and shadow space illusion and other technologies are used throughout the venue to present Van Gogh's paintings in a three-dimensional and three-dimensional manner in front of visitors. Van Gogh's Starry Sky Pavilion uses Van Gogh's works as a carrier to show visitors the bumpy life and many artistic inspirations of this legendary painter. Make visitors immersed in the spiritual world of the artist, and the brilliance of the immortal famous paintings. Accompanied by the melodious music in the venue, visitors can stroll through Van Gogh's paintings, feel the life styles depicted by Van Gogh, and experience the stories and emotions behind each painting. This form has completely subverted the traditional art exhibition form. The whole exhibition hall is more fantasy. The blending of traditional easel painting and high-end technology presents an unprecedented fantasy space for visitors.

Use dynamic images to combine the humanistic environment of open art venues with digital technology, research and make dynamic presentations of every artwork and every antique. Moving originally static cultural relics is not only as simple as digital editing, but also a challenge and mission that every designer should shoulder. It should be regarded as a novel artistic experiment. Dynamic design tends to contain more information than static design, and it is easier for the audience to be emotional.

\subsection{Popularization of dynamic images for science and cutting-edge technology}

Popular science communication is still in an important strategic position for our country. The main role of science popularization is to enable the public to understand science, to understand science, and to get rid of feudal superstition. It is a major step taken by our country to improve the quality of citizens and improve the country's innovation capabilities. However, due to the obscure and high threshold of scientific knowledge, it is difficult for the public to become interested in acquiring scientific knowledge spontaneously. As a visual animal, human beings are naturally sensitive to graphics and text, so dynamic images in the form of video combined with audio can actively attract the public's attention and increase their desire to watch. ${ }^{[4]}$

The traditional science popularization is restricted by the timeliness and the dissemination carrier, so that the audience can only accept it unilaterally. The content creators have no idea about the audience's quality and acceptance of the content. If producers of popular science content want to produce more and better popular science videos that are accepted by the public, they need a network-based feedback mechanism. Therefore, Weibo and WeChat public accounts have become the main types of popular science media accounts.

At the end of January 2018, The WeChat public account 'Paperclip' released the first popular science video 'How to Make an Explosive Coin'. From the traditional paper, dyes, special effects, production equipment, and deeper shading, text selection, decoration and anti-counterfeiting, the manufacturing process of the Ming coin is explained. We have received more than $100,000+$ views on the WeChat platform. What really makes this official account known to the public is the 'Everything About New Coronary Pneumonia' released on February 2, 2020. This popular science video uses the four directions of 'infection', 'spread', 'mask', and 'courage' to address the 'how to infection', 'how to spread', 'mortality rate' and 'The difference with SARS' that the public most want to know and most do not understand since the outbreak. There is detailed data support. This video allows the public to increase their awareness of new coronary pneumonia and spread it spontaneously in the circle of friends. On November 10, 2020, he was invited by CCTV to produce 'How to Dive Ten Thousand Meters Under the Sea' to commemorate the successful conquest of the Mariana Trench by the Struggle.

A popular science public account requires five essential steps to release a high-quality popular science video.

1. Ask questions. To clarify the problem, it is necessary to divide a big problem into a large number of small problems, by studying the internal scientific theory of things, the internal structure and underlying technologies that support the operation of things, and the basic science involved. Obtain the underlying structure technology of a thing and the complete framework of the industrial chain behind it.

2. Data research. The key to collecting information is to quickly find reliable information, and find the 
corresponding professional documents for the corresponding problems. Finding the information does not mean that everything is going well. In fact, no matter what the information in the information is there may be errors. For example, patents with too rudimentary technical methods, outdated standards for measurement methods, and guidance documents generally inconsistent with reality. Journals and papers should pay attention to the source and the reliability of the included papers, and display a large number of files in the video to express the reliability of the information source and ensure that the audience can also find these materials.

3. Narrative logic. Based on a large amount of original materials and information, it is necessary to construct the narrative logic of the problem statement. The most difficult and most important of all kinds of logical relationships is to establish causal relationships. Rooster crowing is related to the rising of the sun, smoking is also related to lung cancer. Data can illustrate the correlation, but to prove causality, you need to have an intermediary connecting the logical chain and exclude the influence of other variables.

4. Text writing. The most important principle for creating text drafts of popular science dynamic videos is to avoid verbose and unintelligible professional terms. Although professional terms can improve credibility and professionalism, they are meaningless if the public does not understand them. This situation can be demonstrated by animation based on the author's understanding, and provide as many details as possible in the text, and finally check the facts and streamline the text in the editing process.

5. Visualization. The key to visualization is to improve the density of information and the efficiency of information transmission, and to present scenes, materials and physical laws in the real world in the video. Through wireframe drawing or 3D model structural animation demonstration, the logic that text is difficult to describe efficiently. This requires repeated communication between the author and the visual designer to ensure that the logic is accurate.

In the Internet age, popular science dynamic images present a cross-grid structure of communication, realizing one-to-one or one-to-many communication. This also lowers the threshold of popular science, but it is inevitable that there will be uneven quality in the process of popular science. As a designer, he must be cautious and subtle when making popular science dynamic films. In terms of cross-discipline, designers should find professionals to verify multiple times and verify from multiple sources. This is not only responsible for the production of popular science videos, but also has a positive effect on the improvement of designers themselves.

\subsection{Popularization and communication of values}

In most people's minds, learning generally involves realtime interaction and communication with teachers in the classroom. For members of the Communist Youth League who want to learn about current affairs and the content of leaders' speeches, they have no way of starting. For members of the Communist Youth League who want to learn about current affairs and the content of leaders' speeches, they have no way of starting. And teenagers are important nodes on the road of life. It is like buttoning a button, the first button is wrongly buttoned, and the next button is wrongly buttoned. Therefore, it is very important to cultivate the values of young people.

The Youth League Central Committee used the WeChat official account as a platform and launched a special course on "Youth Learning" to youth league members in the form of dynamic interactive images. Let young people use their mobile phones to learn the latest policies of the Party Central Committee and learn the correct outlook on life and values in fragmented time anytime and anywhere. This form of learning is more lively and vivid for traditional classrooms and attracts the attention of the public. The accelerated pace of life in the new era makes it difficult for the public to concentrate for a long time. Therefore, "Youth Learning" adopts fragmented learning, which is easier for the public to accept, and people have the desire to learn. The "Youth Learning" course has added assessment content on the basis of ensuring the quality of the content, which is convenient for grasping the learning situation of the public [5]. "Youth Learning" focuses on the original text, interpretation and extension of General Secretary Xi Jinping's important speech, leading the political thinking of young people, serving the growth of young people, analyzing the development situation of the country, paying attention to current affairs and politics, and fostering patriotism.

Internet-based dynamic images show the versatility of content, and the diversification of information is allencompassing but often this information contains a strong author's personal wishes and personal values guidelines. This makes these videos often have extreme, negative, cultural output, and these will also be exposed to young people prematurely, subtly affecting their values. As a designer with a sense of social responsibility, he should avoid bringing personal emotions into the process of editing such images, and educate young people in conformity with the core values of socialism from a fair perspective to produce a more positive impact.

\section{The negative impact of moving images on public perception}

Although dynamic images have brought convenience and cognitive improvement to the public in all aspects of life, a large part of interdisciplinary dynamic images are based on the Internet. Therefore, it is inevitable to fall into the low threshold and make the content quality difficult to guarantee, and the loss of the review process will cause some misleading content to be mixed into it. At the same time, the homogenization and vulgarization of the content are unavoidable, and the public will also be dependent on alignment. In order to avoid the continued seriousness of such phenomena, the content review system must be improved during the dissemination process of dynamic images; responsibility and punishment systems must be formulated. 
The development of dynamic images has become more and more important for the improvement of public cognition. The development of things is always accompanied by twists and turns. While dynamic images could improve public cognition but they will cause information cocoon rooms and solid thinking, etc. problem. ${ }^{[6]}$ However, this does not hinder its development. The large amount of pan-entertainment accompanying dynamic images should be analyzed in detail, and specific suggestions should be made to provide a good reference for the development of dynamic images.

\section{ACKNOWLEDGMENTS}

First of all, I would like to thank the respected $\mathrm{Li} \mathrm{Gu}$ instructor. She has a rigorous academic attitude, which gave me the belief to overcome difficulties. I will keep the attitude of seeking knowledge and exploring, concentrate on learning, and explore my academic field as soon as possible.

\section{REFERENCES}

1. Xie Yanhong, Cross-boundary exploration under new media conditions, Art Education, 2018(10):79-80.(in Chinese)

2. Zhao Zijun, Application of digital media art in cultural creativity- Dunhuang Mogao Grottoes [J]. Western leather,2020,42(19):80-81.(in Chinese)

3. Wang jing, Museum and Moving Images-Historical Information Recording and Dissemination [A]. The Editing Department of Shadow Bo - Influence. [C]. China Film Museum, 2017:4.(in Chinese)

4. Zhang Shuainan, Analysis on the Main Features, Existing problems and Development Suggestions of popular Science self-media [J]. Journal of Beijing Institute of Printing, 202, 28(03):21-25.(in Chinese)

5. Yan Yingxiang, [J]. Youth and Society,2019(12):244245.(in Chinese)

6. Cai Jiasheng, Wang Minglei, Yan Haiyan. Negative impact of we-media communication on public cognition and countermeasures [J]. Media forum,2020,3(19):19-20.(in Chinese) 